\title{
EN TORNO A LA FABULA ILUSTRADA: EL ASTURIANO EUGENIO ANTONIO DEL RIEGO
}

Los últimos intentos de recuperación de una cierta literatura regional, no reflejada en los estudios clásicos de nuestra historiografía, van, poco a poco, dando algunos resultados. Hay que hacer, no obstante, una pequeña aclaración: en la mayor parte de los casos se trata de recuperaciones exigidas desde planteamientos sociológicos o lingüísticos, subordinados, a su vez, a la consecución de un fin sustantivo, cual es la normalización del asturiano como vehículo de comunicación oral y escrita. En un momento en que los estudios sobre nuestra lengua toman un giro rigurosamente no folklórico, la búsqueda y exhumación de textos poéticos y en prosa de los siglos menos conocidos y más apartados de la tradición cultural astur, parece ineludible. Se empiezan a barajar, de nuevo, nombres como los de Antón de Marirreguera, Bruno Cepeda, Balbidares y otros, que cubren las postrimerías del siglo de los últimos Austrias y permanecen, con saltos en la cronología y en la calidad, hasta las primeras manifestaciones del romanticismo, época de la que data la primera antología que recoge este tipo de literatura ${ }^{1}$.

Al hilo de estas generalidades, constatamos cómo la poesía asturiana en sus inicios -que se pueden provisionalmente establecer a partir de Marirreguera, en la segunda mitad del siglo XVII- cuando utiliza la norma bable, permanece indiferente ante los movimientos o escuelas vigentes en el resto del país; un tipo de poesía populista, satírica y realista, sustenta la tradición poética asturiana sin signo alguno, o casual y escaso, de contaminación barroca, que es la escuela en la que se siguen moviendo los poetas de la

1 Ver José Caveda, Colección de poesías en dialecto asturiano. Oviedo, 1839. 
primera mitad del siglo XVIII ${ }^{2}$. Diríase que de existir alguna relación consciente entre poesía asturiana y poesía española, a caballo de los siglos XVII y XVIII, se habría de establecer con modelos como los de Eugenio Gerardo Lobo, frente a los de un José Antonio Porcel o un León y Mansilla; cualquiera que se asome a los versos de El caballo, de Francisco Bernaldo de Quirós, podrá certificarlo. Esta situación se modificará en las últimas décadas del siglo XVIII, bajo la influencia de las corrientes ilustradas, con la desaparición generalizada del poeta extra-social (en un sentido ideológico) procedente de los estamentos nobiliarios - el propio Bernaldo de Quirós- o eclesiásticos -Marirreguera-. Tal parece que los cambios operados en las estructuras sociales del país, a través del fortalecimiento del poder burgués, empujasen a establecer una nueva concepción de la poesía, que ya no será deseada como un divertimento al margen de la realidad sino como una actividad más, compatible con la carrera militar, la vocación científica o la administración pública; éste será el caso de Iriarte, de Jovellanos, de Cadalso, de Forner y de tantos otros. En efecto, en la segunda mitad del siglo, y paralelamente al surgimiento de la poesía ilustrada en el resto del país, advertimos que la poesía、asturiana se sumerge en la misma corriente de renovación, y aunque una serie de rasgos caracterizadores de esa poesía (anecdotismo realista, humorismo, etc.), siguen estando presentes en estos poemas bables, el sello inequívoco de las ideas ilustradas penetra en los escritores, haciendo desaparecer las diferencias que consignábamos en la época barroca; poemas como el de la Bayura asturiana, del dómine Cepeda, o el Debuxu de les funciones que se ficieron na ciudá d'Uvieu pa celebrar la coronación de Carlos $I V$, de Josefa Jovellanos, reflejan la vinculación de los poetas asturianos bables a la escuela que se ha ido imponiendo en el resto del país ${ }^{3}$.

¿Qué ocurre, mientras tanto, con los poetas asturianos que han optado, desde el inicio de su obra, por la norma española? Bastante más ignorados hoy en nuestro país, porque no han podido acogerse a los beneficios que a otros les ha reportado el resurgimiento de la lengua bable, permanecen

2 El caso de Marirreguera es ilustrativo. Su barroquismo está en los temas pero no en las formas, que tienen un colorido específico, de acuerdo con esa tradición realista de la poesía asturiana.

3 Ambos poemas pueden verse en la accesible Esvilla de poesíes na llingua asturiana. Edición, entamu y notes de Xuan Xosé Sánchez Vicente. Oviedo, Biblioteca Popular Asturiana, 1979. 
agazapados tras alguna oscura referencia, casi siempre marginal ${ }^{4}$, a pesar de que su importancia en otros órdenes nos parece indudable; es el caso de los Merás, padre e hijo, de Manuel Rubín de Celis, de Antonio Estrada Nava, del obispo praviano Luis Folgueras y Sión, de Alonso Arango Sierra, de Eugenio Antonio del Riego. De este último vamos a ocuparnos con cierta extensión.

Eugenio Antonio del Riego Núñez nace en Santa Cruz de Tenerife en 1748. Su padre, Nicolás Benedicto del Riego, era catedrático de Derecho; por orden de Felipe V había sido trasladado como Oidor a la Audiencia de Canarias en 1726. A los pocos meses del nacimiento de Eugenio Antonio un nuevo traslado da con la familia en La Coruña, desde donde, en 1755, vuelven a Asturias para asentarse en el solar paterno de Tuña ${ }^{5}$; allí fue Eugenio Antonio Capitán de Milicias, alternando posteriormente la residencia entre Tuña y Oviedo, a causa de la educación que su hijo Miguel ${ }^{6}$ recibía en la capital del Principado. Acogido a los favores del Conde de Campomanes, obtiene en 1787 el cargo de Administrador de la Renta de Correos en Oviedo, donde se establece, con certeza, hasta el año de 1806. Es, en este período de su vida, cuando Eugenio Antonio inicia y culmina sus colaboraciones en la prensa madrileña, cuando, con distintos seudónimos ${ }^{7}$, participa decisivamente en la evolución de un género poético menor, muy expresivo de la época ilustrada: la fábula, que había renacido en el año 1781 con la publicación de las de Samaniego y, un año después, con las de Iriarte, favoreciendo la ruptura de ese género con respecto al apólogo medieval y a la fábula barroca que todavía se cultivaba en la primera mitad del

4 Ver Alberto Gil Novales, Rafael del Riego. La Revolución de 1820 día a día. Madrid, Tecnos, 1976, pág. 32; Nieves Iglesias y Ana María Mañá, Correo de Madrid o de los Ciegos, Madrid, Artes Gráficas Municipales, 1968, pág. XII; José Caso González, «La Sociedad Económica de Asturias desde su fundación hasta 1808", en el Boletín del Centro de Estudios del siglo XVIII, n. ${ }^{\circ} 1$, Oviedo, 1973.

5 Tuña (Tineo), distante $14 \mathrm{kms}$, de la capital del concejo, está situado en uno de los parajes más hermosos del occidente astur; durante los siglos XVII y XVIII debió ser uno de los focos nobiliarios más dinámicos de todo el Principado, por la abundancia de casonas solariegas y palacios que circundan su destrozada iglesia. Tuña es hoy, a nuestros ojos, el reflejo de la incuria cultural de una región desgraciadamente insensible hacia su historia.

6 Miguel del Riego sería después canónigo de la catedral ovetense; exiliado en Londres, huyendo de Fernando VII, reunió la casi totalidad de las poesías de su padre en un volumen publicado en la capital inglesa, en 1842. Un estudio suyo de esta poesía se halla en un manuscrito casi ilegible de la Biblioteca Nacional, 20270, n. ${ }^{\circ} 3$.

7 Así El Aplicado, Genevio Goire, Eudelino Egregio y E.A.D.G.G. 
siglo XVIII ${ }^{8}$. En la principal revista literaria del momento, el Correo de Madrid, entre los años 1789-1792, colabora Riego con todo tipo de obras (romances, pequeños ensayos, odas y, fundamentalmente, fábulas). Del auge que había alcanzado la publicación de estas fábulas dan idea las incesantes noticias en los periódicos de la época, así como los estudios posteriores realizados sobre este período ${ }^{9}$; en un soneto publicado en el mismo Correo de Madrid, el firmante, D. A. D. de S., llega a asegurar que:

«enigmas, himnos, sátiras y liras

en este siglo están de mucha moda» ${ }^{10}$.

$\mathrm{Y}$, ¿qué eran las fábulas, con su cripticismo, sino enigmas para los no iniciados en la sátira política y la diatriba personal? No es en absoluto raro advertir que son muchos - los contemporáneos de esa época- que no llegan a alcanzar en ellas el nivel subterráneo de lectura que implicaban; igualmente miopes han sido los que, perezosamente, han venido sosteniendo su estricto carácter moralizador y didáctico, perpetuando un tipo de análisis que no ha sabido interpretar la supuesta finalidad inicial de estos pequeños textos ${ }^{11}$. Varios meses más tarde, aparece en el Correo una crítica elogiosa de las fábulas de Samaniego firmada por J. G. R., en la que se ensalza el genio versificador del riojano «hasta para unas materias que parecen tan triviales y bajas como son en sí las fábulas» ${ }^{12}$.

Pues bien, en ese proceso de adecuación a las pretensiones racionalistas propuestas por el reformismo burgués en las últimas décadas del siglo, inicia Eugenio Antonio del Riego, desde Asturias, la publicación de sus fábulas, con una carta al editor de la que reproducimos algunos fragmentos significativos:

«Señor Editor. Somos tan raros en nuestras ideas, que cuando pensé nunca hacer fábulas, solo por haber leído la carta que Vmd. insertó del señor Azpeitia ${ }^{13}$, caí en la tentación de probar, ¿qué cosa sería esto?

8 Ver José María de Cossío, Fábulas mitológicas en España. Madrid, Espasa-Calpe, 1952, 907 págs.

9 Pueden verse, entre otros, los de Menéndez y Pelayo, Urquijo, G. Germain, Angel del Río, Bosch-Cere, Sebold...

10 Correo de Madrid, 22-7-1789 (n..$^{\circ} 278$ ), pág. 2.240.

11 Recuérdese que Samaniego, en la primera edición de sus Fábulas dedica el Libro Primero «a los caballeros alumnos del Real Seminario Patriótico Vascongado».

12 Correo de Madrid, 12-12-1789 (n. ${ }^{\circ} 318$ ), pág. 2.555.

13 Hace referencia a la "Carta contra los malos fabulistas», de Sancho de Azpeitia, publicada en el Correo de Madrid (n. $\left.{ }^{\circ} 330\right)$, 1790, págs. 2.650-2652. 
Medité sobre ello, me ensayé, y después de haberlo reflexionado, concluí para mí en tres cosas. La primera que el hacer una fábula solamente mediana tiene no pequeña dificultad, por lo que me parece son muy dignos de estimación todos los que nos instruyen en este ramo, pues se puede sacar de él más utilidad que no de otras muchas clases de composiciones, aunque sean más fluidas y más sublimes (...).

La tercera cosa que concluí (que viene a ser como el resultado de todo este trabajo y motivo de esta carta) es mi ensayo en las dos adjuntas composiciones, que si no mereciesen el nombre de fábulas, serán cuentos, ensaladillas o como quisiesen llamarlas. Haga Vmd. el uso que gustase de ellas y de esta carta mientras se repite muy suyo y B.L.M.

El Aplicado» ${ }^{14}$.

Inmediatamente, advertimos en este texto dos cuestiones del mayor interés: a) el hacer fábulas tiene no pequeña dificultad; b) si lo que Riego escribe no son fábulas, serán cuentos, ensaladillas o como quisiesen llamarlas.

En el primer caso, ¿a qué dificultades se refiere el autor? Sabemos perfectamente que en este momento se están escribiendo en España muchísimas fábulas; unas, las menos, aparecen abiertamente formando volumen, como las de Ibáñez de la Rentería, que salen de la prensa un año antes de este texto, en 1789; otras se publican en los periódicos, por el sistema de entregas, como las del propio Riego; pero, gran cantidad de ellas son manuscritas, corren clandestinamente de mano en mano; son, como atestigua Sempere, «sátiras injuriosas, libelos infamatorios contra los sujetos más beneméritos de la literatura» ${ }^{15}$. Por otra parte, y abundando en todo ello, Forner asegura que «el hacer una fábula no tiene más reglas que el antojo», por lo que no le extraña que «el gusto está hoy más inclinado a las fábulas que a las verdades ${ }^{16}$.

Las dificultades a que se refiere Riego no parecen, por lo que acabamos de decir, ser formales, puesto que estamos viendo que para hacer una fábula no se necesitan dotes especiales de versificación; el mismo Forner, en el Prólogo citado, asegura: «En nuestros días quieren decir algunos que el hacer fábulas es negocio de mucha dificultad (...) el que forme buenas

14 Correo de Madrid, 17-2-1790 (n. ${ }^{\circ} 337$ ), pág. 2.711. El subrayado del texto es nuestro.

15 Ver Juan Sempere y Guarinos, Ensayo de una biblioteca española de los mejores escritores del reynado de Carlos III. Edición facsímil. Madrid, Imprenta Real, 1785-1789. Madrid, Gredos [1969]. Pág.

16 Juan Pablo Forner, prólogo de El Asno Erudito, reedición en Valencia, Castalia, 1948, pág. 57. Edición original de 1782. 
letrillas, buenos romances, buenos satíricos poemas o burlescos, formará, si quiere, apólogos igualmente buenos» ${ }^{17}$. Nos inclinamos a pensar que Riego habla de dificultades superestructurales y que, para él, la situación social y política por la que atraviesa el país no es ajena, en modo alguno, a esas dificultades. Consciente de que la fábula, en cuanto género poético, ya no está sirviendo los intereses puramente didácticos o ejemplificadores, por la continua traslación de préstamos satíricos, sociales y aún políticos que está teniendo lugar en esos momentos (y que había ya comenzado casi diez años antes, con Iriarte y Samaniego), vacila a la hora de llamar a sus versos fábulas; de ahí que, en el tercer párrafo de la carta al editor, tenga conciencia de la ambigüedad que supone presentar como fábulas una serie de poemas que «serán cuentos, ensaladillas o como quisiesen llamarlas». No se puede olvidar que la fábula, al igual que otros productos literarios de esta época, vive sometida -en el contexto de lucha ideológica existente en el país- a las mismas leyes de autocensura y represión que se han desatado desde la muerte de Carlos III, siendo los fabulistas muy sensibles a ese contexto. La sombra amenazante de los sucesos franceses se cierne sobre la monarquía española y la política gubernamental experimenta una fuerte involución que obtura los conductos ilustrados de vanguardia. Todavía en vida de Carlos III, en agosto de 1787, Ibáñez de la Rentería había publicado en el Diario de Madrid la fábula El Raposo ${ }^{18}$; inmediatamente Floridablanca, sintiéndose aludido, ordena la búsqueda y prisión del autor, que, gracias a los buenos oficios de Samaniego, pudo salir indemne del lance.

Riego, insistimos, sabe que las fábulas ya no van dirigidas exclusivamente a bachilleres y alumnos de las Sociedades y que, con el paso del tiempo, han ido adquiriendo un carácter mucho más pragmático, pasando a proponer una revisión de los conceptos que definían su naturaleza; mientras

17 Forner, pról., cit., pág. 56.

18 Diario de Madrid, 4-8-1787. Por ejemplo:

$$
\begin{aligned}
& \text { « } \text { Por qué para estos casos } \\
& \text { buscamos en los brutos ejemplares, } \\
& \text { si de iguales fracasos } \\
& \text { nos ofrecen los hombres centenares } \\
& \text { cuando el poder usaron con exceso?» }
\end{aligned}
$$

Samaniego logró convencer al ministro de que la fábula había sido escrita bastantes años antes, por lo que no podía interpretarse como un ataque a personas o situaciones concretas.

Un interesante análisis global de las fábulas de Ibánez se halla en Luis María Areta Armentía, Ideas y realizaciones literarias de la Real Sociedad Vascongada de los Amigos del País (tesis doctoral, de la que no nos consta su publicación). 
esa revisión no se efectúe por parte de escritores y apologistas, aceptará, sólo provisionalmente, el término común de «fábula».

En agosto de 1790, seis meses más tarde de su iniciación, Riego concluye las treinta y seis primeras composiciones, que pueden, según él piensa, constituir un pequeño libro ${ }^{19}$; el relativo éxito que obtienen estas fábulas, por parte de los suscriptores del Correo de Madrid, anima al autor a continuar por el mismo camino y un segundo libro de fábulas se presenta al editor, al que va dirigido este significativo prólogo:

«Señor editor: No obstante que he dado por fenecido mi ensayo sobre fábulas y que en su conclusión insinué esperaba el dictamen del señor don Sancho de Azpeitia, me ha parecido continuarlas en segundo libro, atendiendo a la aprobación que han merecido a su censura pública y haberme asegurado familiarmente ser del gusto de otros.

La materia es muy útil y tan amena como extensa, y pudiera hacerse mucho más útil, si al mismo tiempo que particularizando más los ejemplos (sin atenerse sólo a máximas generales, como hasta ahora han hecho los fabulistas), se les diese cierto orden que fijase más bien la doctrina, como dividiéndola por clases en morales, políticas, económicas, científicas, etc. Pero vea Vmd. aquí que ésta no es obra para mí, cuando no sea por defecto de la instrucción necesaria, porque no se aviene bien con mis ocupaciones.

Básteme manifestar el deseo para despertar el gusto de otros, contentándome con lo poco que puedo y of rezco con buena voluntad al público por medio de su periódico de $V_{m d}$.

De quien se repite su más atento servidor Q.B.S.M.

El Aplicado» 20 .

Nos encontramos ante un texto que no dudamos en calificar de clave para la comprensión de lo que venimos sosteniendo. La fijación del género fábula está a punto de consumarse; Riego acaba de desbrozar una serie de elementos que venían enlazándose confusamente en los estadios precedentes del género, elementos que sumían a las fábulas en una grave inconcreción, excesiva para la mentalidad racionalista de los ilustrados; a partir de aquí disminuyen las fábulas «literarias» y aumentan las «políticas», «militares», «satíricas», etc. No es, pues, casual el hecho de que hasta 1790, aproximadamente, los títulos de los fabularios eludan manifestar sus contenidos o los temas y asuntos que van a ser tratados; las fábulas son literarias en Iriarte (1782), son en verso castellano para Samaniego (1781) y para

19 Ver el «Epílogo o conclusión sobre las fábulas anteriores», en el Correo de Madrid, 18-8-1790 (n. $\left.{ }^{\circ} 388\right)$, pág. 287.

20 Correo de Madrid, 25-8-1790 (n. ${ }^{\circ} 390$ ), pág. 302. 
Ibáñez de la Rentería (1789), son alegóricas en Donato de Arenzana (1789), son, en fin, morales -lo cual supone un cierto esfuerzo en evitar la ambigüedad- para Bernardo María Calzada (1787); comparando todos estos títulos con aquellos que aparecen a partir de 1790 percibimos fácilmente la singular novedad ${ }^{21}$.

¿Quiere esto decir que todos los libros de fábulas que se publican con posterioridad a esa fecha-1790- confirman lo que venimos sosteniendo? No en todos los casos. A pesar de que el uso de la etiqueta «políticas», «militares», «satíricas», etc., comienza a generalizarse en el título de los fabularios ${ }^{22}$, en algunas ocasiones los fabulistas siguen acogiéndose a la indeterminación inicial. No obstante, y esto es lo que verdaderamente interesa, la finalidad de los pequeños poemas es otra; los autores hacen emerger a la superficie del texto las funciones que el género venía cumpliendo, latentemente, años antes: deleitar, no enseñando principios morales de orden abstracto, sino descubriendo hechos reales (políticos, sociales, religiosos); hasta tal punto esto es así que, muchos años después, en 1820, el aragonés Rafael José Crespo, consciente de no seguir los nuevos modelos que se han ido imponiendo, intenta defenderse contra toda posible crítica, por la falta de originalidad de sus fábulas, en un prólogo que las precede ${ }^{23}$; por otra parte, en los títulos de un Folgueras y Sión, de un Azcuénaga o de un Pablo de Jérica, no aparecen reflejadas las nuevas tendencias y, sin embargo, el propio Jérica dirá de sus fábulas que «los liberales, especialmente los jóvenes, las estiman; y los serviles sobre todo los fanáticos, las detestan» ${ }^{24}$.

De esta manera, y a través del proceso que hemos venido esbozando, se acaba cumpliendo una de las permanentes aspiraciones de las élites ilustra-

21 De la importancia e influencia que tuvo la nueva clasificación de la fábula en sus varios subgéneros, da idea el hecho de que, en época tan avanzada como 1842, Ramón de Campoamor divide sus $F$ ábulas originales en literarias, políticas, morales, religiosas y filosóficas. El poeta de Navia no hacía más que seguir una norma que se había iniciado en la referida fecha de 1790, gracias a la intuición ilustrada de su paisano Riego.

22 Así en autores como Valvidares y Longo, Cristóbal de Beña, Marqués de Casa Cagigal, Dueñas y Luján, Mendizábal y otros que pueden rastrearse hasta la segunda década del siglo XIX.

23 La falta de originalidad consistiría en reproducir los viejos modelos (Esopo, Fedro, La Fontaine, Hagedorn, y aún Iriarte y Samaniego), marginándose de las nuevas exigencias que reclamaba el público iniciado.

Ver Rafael José Crespo, Fábulas morales y literarias, Zaragoza, 1820.

24 En el prólogo de sus Poesías, Bordeaux, 1831, 184 págs. 
das españolas: poner al servicio de amplias capas de lectores una literatura útil, amena y vigilante; una literatura que sintonizase con los esfuerzos reformistas que, en otros terrenos, constituían la base medular de sus conductas. Si los fabulistas del siglo XVII, y los que cubren el transcurso casi total del XVIII, no entendieron el guiño del viejo apólogo castellano, mediatizados por la imaginería literaria barroca, acaban, en el último cuarto de siglo, devolviendo las fábulas al mundo de la vida y la pasión cotidianas.

A Eugenio Antonio del Riego Núñez, burócrata aficionado a hacer versos -no siempre perfectos, como juzga Jovellanos en los Diarios- ${ }^{25}$ le corresponde, no obstante, el mérito indudable de haber presentido la naturaleza y el cambio de aplicación de las fábulas, de haber advertido al público lector sobre las cualidades ocultas de su mensaje:

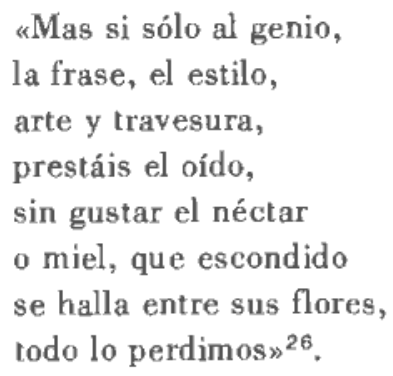

Porque, en definitiva, aquella poesía menor, y a menudo fútil, que inunda los principales periódicos españoles finiseculares ${ }^{27}$, termina hallándose en la encrucijada a la que están abocados todos los fenómenos de comunicación literaria: unir, lo más perfectamente posible, arte y compromiso en un mismo discurso.

\author{
Alvaro Ruiz de la PEÑa \\ Universidad de Oviedo
}

25 Debe decirse que don Gaspar Melchor aborrecía las composiciones poéticas de Riego. Era para él un delicado problema dar su juicio sobre los versos que el administrador de Correos le enviaba con terca frecuencia; expresiones del tipo «no hay por donde tomarlos", aparecen haciendo referencia a los poemas de Riego, en cuatro o cinco ocasiones.

26 Prólogo al Libro Segundo de sus fábulas, en Correo de Madrid, 25-8-1790 (n. ${ }^{\circ} 390$ ), pág. 302 .

27 Ver, a tal efecto, el exhaustivo trabajo de Francisco Aguilar Piñal, Indice de las poesías publicadas en los periódicos españoles del siglo XVIII, Madrid, C.S.I.C., 1981. La abundantísima nómina de fabulistas, que suelen esconder su personalidad tras un seudónimo o las siglas más indescifrables, refleja el grado de interés que este tipo de poemas llegó a tener en las últimas décadas del siglo. 